\title{
Hormones, hormonal agents, and neuropeptides involved in the neuroendocrine regulation of sleep in humans
}

\author{
Grigorios Kotronoulas ${ }^{1}$, Antonios Stamatakis ${ }^{2}$, Fotini Stylianopoulou ${ }^{2}$ \\ ${ }^{1}$ Cancer Care Research Centre (CCRC), University of Stirling, Stirling, Scotland, UK; HESMO Scholar (2009-2010), \\ ${ }^{2}$ Laboratory of Biology-Biochemistry, Faculty of Nursing, University of Athens, Athens, Greece
}

\begin{abstract}
Sleep is an essential ubiquitous biological process, a periodical state of quiescence in which there is minimal processing of sensory information and no interaction with conspecifics or the environment. Despite relevant research on sleep structure and testing of numerous endogenous sleep-affecting chemicals, questions as to the precise mechanisms and functions of sleep remain without satisfactory responses. The purpose of this review is to report on current evidence as regards the effect of several endogenous and exogenous hormones, hormonal agents, and neuropeptides on sleep onset or wake process, when administered in humans in specific doses and via different routes. The actions of several peptides are presented in detail. Some of them (growth hormone releasing hormone, ghrelin, galanin, neuropeptide Y) seem to promote sleep, whereas others (corticotropin, somatostatin) impair its continuity.
\end{abstract}

Key words: Ghrelin, GHRH, Hormones, Melatonin, NPY, Neuroendocrine regulation, Neuropeptides, Sleep, Sleep disorders, Wakefulness

\section{INTRODUCTION}

Sleep is an essential ubiquitous biological process, a periodical state of quiescence in which there is minimal processing of sensory information and no interaction with conspecifics or the environment. ${ }^{1,2}$ However, sleep is more than the absence of being awake; it is a homeostatically regulated process, without the revitalising force of which survival might not be feasible. ${ }^{3,4}$

\section{Address for correspondence:}

Grigorios Kotronoulas, University of Stirling,

351 Fraser Street, Stirling, FK9 4LE, Scotland, UK,

Tel.: +44 (0) 7556 284180, E-mail: gkotronoulas@gmail.com

Received 24-05-09, Revised 05-08-09, Accepted 10-09-09
One difficulty in understanding sleep is that it is not a unitary state but a combination of two substates of distinct brain activity actively generated in specific brain regions. ${ }^{1,2}$ Therefore, sleep definition requires the combined input from an electroencephalogram (EEG), an electrooculogram (EOG), and an electromyogram (EMG). The resulting polysomnogram identifies the sleep state and stages. ${ }^{5}$ One state is characterised in most mammals by Rapid Eye Movements (REM) and is usually termed REM Sleep (REMS); the other, in which no rapid eye movements occur, is known as non-REM Sleep (NREMS). In humans, NREMS is usually subdivided into stages $1-4$, which correspond roughly to increasing depth of sleep and decreasing muscle tone. ${ }^{2}$ Stages 3 and 
4 are often grouped together under the label "Slow Wave Sleep" (SWS). ${ }^{5}$ In NREMS a large increase of growth hormone $(\mathrm{GH})$ secretion, together with suppression of cortisol secretion is observed. ${ }^{5,6}$ REMS is a completely different sleep stage, characterized by a virtual absence of muscle tone in antigravity muscles, a largely awake brain, and dreaming. It is of interest also that the metabolic rate in NREMS is increased above resting waking levels. ${ }^{5,6}$ In the normal sequence (called "sleep architecture"), waking is followed by NREMS's lighter stages ( 1 and 2 ) and then within 10 to 20 minutes by SWS. These stages of deeper sleep are maintained for nearly one hour in normal young subjects but are much shorter (5-10 $\mathrm{min}$ ), if present at all, in older individuals. Lighter stages of NREMS then re-appear and the first REM period is initiated. ${ }^{1}$ This cycle is repeated three to four times during the night but with decreasing amounts of SWS and increasing amounts of REMS. ${ }^{5}$ Each stage of sleep has a characteristic EEG frequency and waveform. ${ }^{5,7}$

The timing, duration, and depth, or intensity, of sleep is regulated by two interacting processes: a homeostatic that maintains the duration and intensity of sleep within certain boundaries and a circadian which determines the timing of sleep and governs several physiological variables, including core body temperature and the production of hormones such as cortisol and melatonin. ${ }^{2}$ The interaction of the homeostatic and circadian facets of sleep regulation has been formalised in the two-process model of sleep regulation. ${ }^{8,9}$

The simultaneous application of electrophysiological and neuroendocrinological methods in normal men and women under baseline conditions and after administration of synthetic and active endogenous central nervous system (CNS) compounds has shown (a) a considerable activity of various endocrine systems during sleep, and (b) a bidirectional interaction between the electrophysiological and neuroendocrine components of sleep..$^{10,11}$

The nocturnal secretion of various hormones shows distinct patterns. During the first half of the night a surge of growth hormone $(\mathrm{GH})$ predominates, whereas adrenocorticotropin (ACTH) and cortisol levels are low; during the second half, ACTH and cortisol rise, whereas GH declines. This pattern suggests (a) a reciprocal interaction of the hypothalamo-pituitary somatotrophic (HPS) and the hypothalamopituitaryadrenocortical (HPA) axes, their peripheral endpoints being GH and cortisol, respectively, and (b) the existence of common regulators of sleep EEG and sleep-related hormone secretion. A sexual dimorphism of sleep-endocrine activity has been found in young normal subjects: cortisol levels are higher in females than in males and most male subjects show a single GH peak around sleep onset, whereas females show a pre-sleep GH surge and additional GH peaks during the second half of the night. ${ }^{12}$

Obviously, bidirectional interactions exist between sleep and the endocrine system..$^{13}$ Several hormones have the capacity to affect sleep but the physiological significance of hormonal modulation of sleep is generally unclear. Plasma concentrations of many hormones display sleep-related variations, suggesting that sleep influences hormone secretion. However, sleep and hormone levels may run in parallel without a cause-effect relationship. For instance, circadian regulation may synchronise these events. Interestingly, even though in the past fifty years much has been learned about sleep structure ${ }^{11}$ new functional pathways of sleep are continuously being uncovered and a whole range of novel agents appear linked to them. The purpose of the present review is to provide an updated overview of literature data regarding the effect of several endogenous and exogenous hormones, hormonal agents, and neuropeptides on the sleep onset or wake process (Figure 1) in humans, as well as their relevance to pathological conditions resulting in altered sleep patterns.

\section{GROWTH HORMONE-RELEASING HORMONE (GHRH)}

The endogenous substance with a well documented sleep-promoting activity is GHRH. ${ }^{10}$ Besides its well-known function in stimulating pituitary $\mathrm{GH}$ release, GHRH may have a direct role in promoting NREMS. ${ }^{14,15}$ The GHRH-induced NREMS is characterised by supranormal EEG slow waves. After central and systemic administration of GHRH, duration and intensity of SWS increase in humans. ${ }^{16}$ However, negative outcomes have been reported as well. ${ }^{17}$ In 


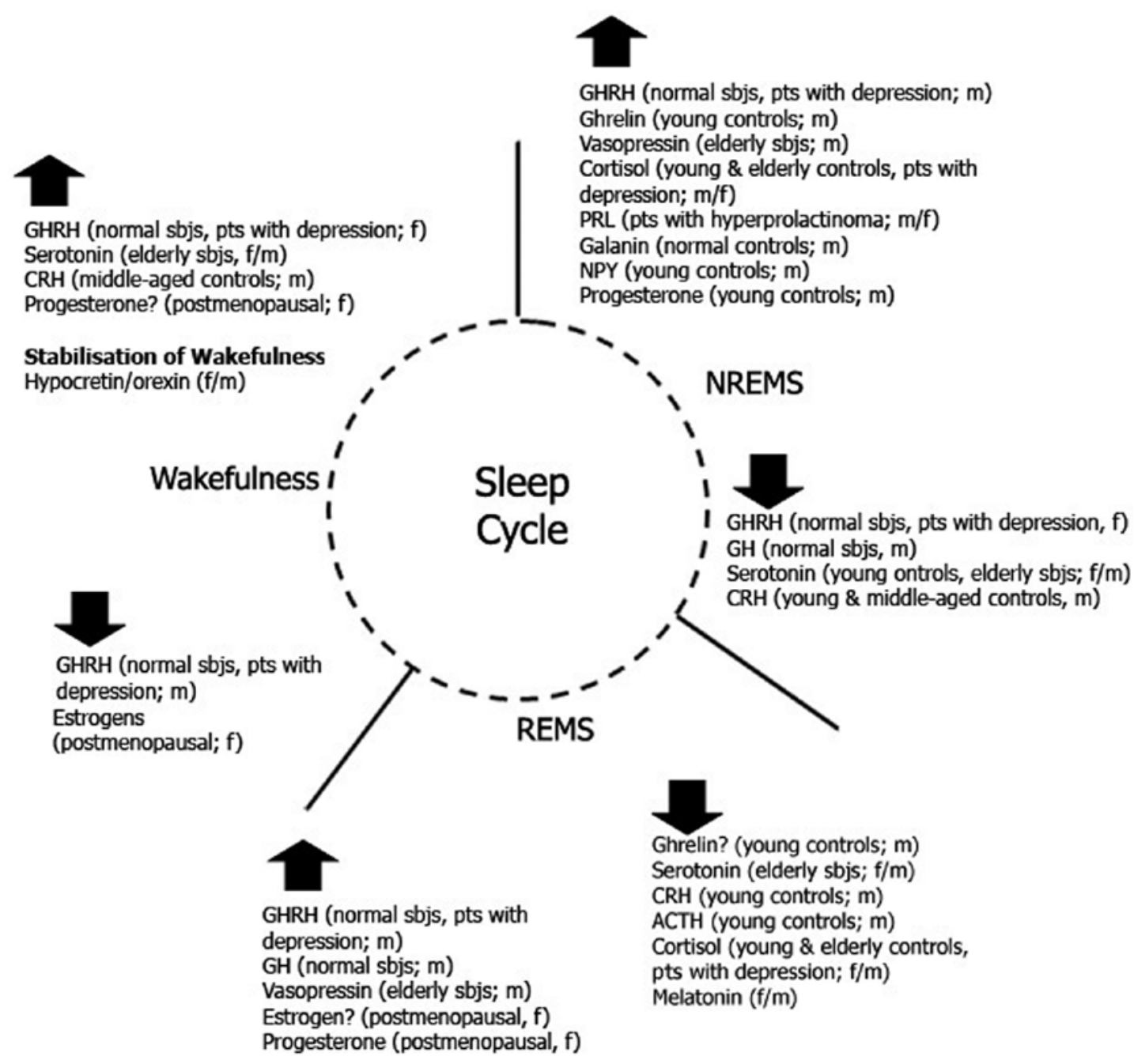

Figure 1. The effect of hormones and hormonal agents on the sleep-wake cycle in humans [pts: patients; sbjs: subjects; m: male; f: female; $\uparrow:$ increase; $\downarrow$ : decrease; ?: inconsistent effect].

addition, no change ${ }^{14}$ or decrease in REMS during the first half of the night ${ }^{18}$ has been observed.

In humans, the frequency of delta waves during the first $100 \mathrm{~min}$ of sleep was significantly enhanced following bedtime injection of GHRH. ${ }^{15}$ When the injections were given during sleep, stimulatory effects on SWS were observed. ${ }^{19}$ However, no major changes of sleep EEG were found after repetitive i.v. GHRH during the early morning hours. ${ }^{20}$

The sleep-promoting activity of GHRH varies with age and gender in humans. ${ }^{21}$ Strong responses have been observed in young subjects, with sleep promotion after i.v. ${ }^{15}$ and intranasal ${ }^{22}$ administration of GHRH. In the elderly, instead of enhancing SWS, GHRH increases stage 2 NREMS and sleep continuity. Steiger et $\mathrm{l}^{14}$ tested the effect of repetitive i.v. boluses of GHRH during the first few hours of the night in young normal men. After GHRH infusion, SWS and GH secretion increased and cortisol decreased. An increase in NREMS and a decrease in wakefulness were observed during the recovery night in normal, sleep-deprived men and women after repetitive administration of GHRH. ${ }^{23}$ On examining the effect of intranasal administration of GHRH in young and aged humans, Perras et $\mathrm{al}^{22}$ found that intranasal GHRH reduced cortisol nadir concentrations at the beginning of sleep and reduced the sleep-induced elevation in $\mathrm{GH}$ concentrations during early sleep. SWS increased, with this influence primarily exerted 
during the second half of sleep time.

In a study by Guldner et al, ${ }^{24}$ the effects of GHRH on sleep were examined in three states with a change of the GHRH/CRH ratio in favour of CRH. It was concluded that only a weak sleep-promoting effect of GHRH was found in the elderly. ${ }^{24}$ GHRH does not seem to promote sleep in females. A sexual dimorphism in response to GHRH was also found in drugfree patients with depression and in controls. ${ }^{25}$

If endogenous GHRH is a physiological NREMSregulatory substance, then its suppression should be associated with decreases in NREMS. ${ }^{13}$ This point of view has been widely studied. A competitive GHRH antagonist ${ }^{26}$ elicited dose-dependent decreases in the duration and intensity of NREMS and increases in sleep latency. Moreover, injection of a GHRH peptide antagonist into the same area where GHRH is injected inhibits NREMS and attenuates sleep rebound after sleep deprivation. ${ }^{27}$ Furthermore, intracerebroventricular (i.c.v.) administration of antibodies to GHRH decreases NREMS in patients with depression. ${ }^{23}$ Affinity-purified antibodies to GHRH significantly suppress both NREMS and REMS for at least 12 hours during the light (rest) period and prevent the sleep rebound that normally occurs after $3 \mathrm{~h}$ of sleep deprivation. ${ }^{28}$ While GH deficiency (GHD) often reflects hypothalamic GHRH deficiency in aged subjects, so far GHRH replacement therapy has not yielded consistent improvements in sleep, possibly due to lack of sustained activity throughout the night. ${ }^{29}$ On the other hand, various types of benign tumours may lead to ectopic, peripheral GHRH hypersecretion, causing GHRH-associated acromegaly. ${ }^{30} \mathrm{In}$ these patients, feedback inhibition of GHRH may contribute to the decrease of SWS.

\section{GHRELIN \& ANALOGUES}

Ghrelin is the recently isolated endogenous ligand of the orphan GH secretagogue (GHS) receptor type 1a (GHS-R1a). ${ }^{31,32}$ Like synthetic GHS, ghrelin possesses a strong GH-releasing effect in humans. ${ }^{33,34}$ Furthermore, ghrelin enhances HPA hormones and prolactin when given during the daytime. ${ }^{35}$

Ghrelin itself has recently been reported to be a sleep-promoting factor in humans. Similarly to GHRH, repetitive i.v. ghrelin administration en- hanced SWS, Slow Wave Activity (SWA), and GH in young normal males. ${ }^{36}$ In a recent study, ${ }^{37}$ sleep EEG and the nocturnal levels of ghrelin were examined simultaneously. A trend was found suggesting a lower time spent in stage I sleep in subjects with high nocturnal ghrelin levels. However, the authors suggested that under normal conditions plasma ghrelin levels show no distinct interaction with sleep. ${ }^{37}$ Other studies have demonstrated that when ghrelin was administered in early morning, it did not affect sleep in 12 healthy males. ${ }^{38}$

On the other hand, in two studies acute administration of the synthetic peptidyl GHS, MK-0677, modified the sleep pattern in normal subjects. ${ }^{39,40} \mathrm{In}$ fact, prolonged treatment with oral MK-0677 (25 mg once daily) in elderly subjects increases the length of REM sleep phases, meanwhile decreasing rapid eye movement latency. ${ }^{41}$ Hexarelin, another synthetic GHS, exerts similar actions by decreasing stage 4 sleep during the first half of the night and EEG delta power during the entire night. ${ }^{42}$

\section{SOMATOSTATIN (SRIH) \& ANALOGUES}

SRIH inhibits hypothalamic GHRHergic neurons (thus, GHRH release) and, after being released into the pituitary circulation, leads to inhibition of GH secretion directly in the pituitary. ${ }^{13}$ SRIH has five receptors named sst1 to SST5. Inhibition of the somatotropic axis is mediated by the SST2 receptors. An unbalanced gain on chromosome $17 \mathrm{q}$ and promoter polymorphisms have been shown to play a role in the regulation of SST2 receptor expression, increasing overall and event-free survival in pediatric patients with neuroblastoma. ${ }^{43}$

SRIH inhibits NREMS, presumably via its effects on GHRH secretion and stimulates REMS. ${ }^{4}$ Interestingly, SRIH's action shows an age-dependence. Repetitive i.v. administration impaired sleep in healthy elderly subjects, ${ }^{44}$ whereas the same substance had no effect on young normal men. ${ }^{14}$ These data suggest a reciprocal interaction of GHRH and SRIH in sleep regulation similar to their action on $\mathrm{GH}$ release. This theory is further supported by the fact that arginine, a SRIH antagonist, given as an infusion, increased SWS in elderly men, probably through enhancement of endogenous GHRH secretion. ${ }^{45}$ 
The half-life of SRIH within tissues is only a few minutes. Therefore, instead of SRIH, hydrolysis-resistant analogues, such as octreotide, are often used experimentally. Octreotide stimulates SST2 and SST5 receptors and is more potent than exogenous SRIH.${ }^{13}$ Octreotide-induced impairment of NREMS has been verified in humans after subcutaneous infusion. ${ }^{46}$ After $1-3 \mathrm{~h}$ postinjection, when intensity of NREMS increases, the accumulated GHRH is gradually released from the hypothalamus. Therefore, a possible explanation for the biphasic sleep response to octreotide is that octreotide suppresses sleep via inhibiting GHRH release, and this period is followed by excessive GHRH release and deep NREMS. ${ }^{13}$

Recently, two novel neuropeptides have been discovered (Urotensin II, Cortistatin). Interestingly, despite structural similarity of these peptides to SRIH, their sleep-related actions differ widely. Urotensin II is considered to be involved in REMS regulation, ${ }^{47}$ while cortistatin has been shown to induce SWS. ${ }^{48}$ SRIH analogue treatment is usually prescribed in acromegaly patients, in whom increased daytime sleepiness as well as delayed sleep onset have been reported. ${ }^{49}$

\section{CORTICOTROPIN-RELEASING HORMONE (CRH)}

Various human studies have shown that administration of HPA hormones or their antagonists affect sleep. The common denominator of the effect of the HPA axis on sleep EEG is CRH, which decreases SWS and increases wakefulness. ${ }^{5}$

Pulsatile i.v. boluses of human CRH $(4 X 50 \mu \mathrm{g})$ in young normal male subjects led to a decrease in SWS with an increase in light sleep and awakenings. ${ }^{50}$ The time interval, the dosage, and the protocol of the administration appear to be crucial methodological issues. As a matter of fact, whereas after continuous nocturnal infusion of CRH the sleep EEG remained unchanged, ${ }^{51}$ EEG spectral variables were altered after a single i.v. bolus of $\mathrm{CRH}$ in young healthy men. ${ }^{52}$ Conversely, in sleep-deprived healthy humans, $\mathrm{CRH}$ induces higher increases in NREMS if given during the recovery night compared to placebo. ${ }^{23}$ The responsiveness of sleep EEG to CRH appears to increase during ageing, since sleep disruption with $\mathrm{CRH}$ is more pronounced in middle-aged men compared to young men. ${ }^{53}$ In young men, sleep EEG remained unchanged; in middle-aged subjects, however, wakefulness increased and SWS decreased. $\mathrm{CRH}$ antagonists have also been used to study the impact of CRH on sleep-EEG, but the results are conflicting. ${ }^{10} \mathrm{CRH}$ can contribute to both stressed and non-stressed waking. This waking effect is consistent with an increase in light sleep in humans given exogenous $\mathrm{CRH}^{50}{ }^{5}$ More importantly, $\mathrm{CRH}$ has an arousing and waking effect even in the absence of stress. $^{54}$ The hypothesis that $\mathrm{CRH}$ promotes REMS is also supported..$^{50}$ However, it is claimed that the influence of endogenous CRH on REMS is uncertain as the amount of REMS decreases after $\mathrm{CRH}$. Similarly, in a study of depressed patients, a CRH antagonist decreased REM latency after short-term but not long-term administration. ${ }^{55}$

Furthermore, it has been proposed ${ }^{7}$ that MR and GR receptors (see §6) can modify CRH levels by being either activated or suppressed via their feedback relationships with CRH. CRH suppression is enhanced by MR mediated inhibition at the paraventricular nucleus (PVN). This would augment CRH suppression in the early sleep period and at the time of the nocturnal nadir, when SWS is expected to occur. On the other hand, excessive GR activation at the level of the amygdala (as opposed to inhibition at the PVN) may activate CRH and decrease SWS. A HPA axis overdrive, due to enhanced secretion of CRH combined with an impaired negative feedback via GR, seems to be most consistently observed in patients with depressive features ${ }^{56}$ and has been suggested as a potential biomarker for depression. Depressed patients show clear sleep-EEG alterations, including disrupted sleep, low amounts of SWS, a short REM latency, and a high REM frequency.

It has been proposed that the downregulation of CRH activity is a final and common step of antidepressant treatment. In a recent study, three polymorphisms in the CRH receptor 1 (CRHR1) gene were tested in conjunction with six weeks of antidepressant treatment in patients suffering from major depressive disorder (MDD). The polymorphisms were associated with differential therapeutic response to antidepressants in patients with high-anxiety, supporting the idea that the CRHR1 gene is likely to be related to the antidepressant response in MDD. ${ }^{57}$ 


\section{ADRENOCORTICOTROPIN (ACTH)}

In clinical studies, nocturnal infusions of ACTH suppress REMS in normal subjects, ${ }^{58}$ while cortisol and GH stimulates REMS. ${ }^{51}$ An experiment in healthy volunteers showed that the expectation of waking up at a certain time induces a marked increase in ACTH before the end of sleep. ${ }^{59}$ The researchers studied the levels of ACTH in association with sleep termination under three experimental conditions: an early planned awakening, a late planned awakening, and a surprise condition in which sleep was terminated earlier than expected by the subjects. Arousal from sleep in each of the three conditions prompted an increase in ACTH and cortisol. The most interesting finding was that the early planned awakening was preceded by a distinct increase of ACTH within the last hour before waking, while ACTH secretion surge occurred only after sleep termination in the surprise condition, in which the subjects did not expect to be awakened at this particular time. ${ }^{5}$ This change was interpreted as an adaptive response to the stress of waking. The anticipatory increase in ACTH may facilitate spontaneous waking. ${ }^{5}$ It remains unclear whether or not ACTH participates in sleep regulation $^{60}$ or the observed changes represent an associated phenomenon.

\section{CORTISOL, GLUCOCORTICOID, AND MINERALOCORTICOID RECEPTOR LIGANDS}

The human endogenous cortisol rhythm is characterised by a nadir that takes place at about midnight, ${ }^{7}$ followed by a rise at about 2-3 hours after sleep onset that continues into the early waking hours. A cortisol peak occurs at about 09:00. As the day continues, a gradual decline in cortisol levels occurs leading to the nadir at about midnight.

In brain, cortisol preferentially binds to high affinity mineralocorticoid receptors (MR, type I) in the hippocampus and to low affinity glucocorticoid receptors (GR, type II) in the hypothalamus, pituitary, cortex, and elsewhere ${ }^{61}$ and modulates the underlying circadian rhythm. The effect of MR predominates in the early nocturnal period and is most prominent at the time of the nocturnal nadir. In contrast, the effect of GR dominates in the morning when cortisol levels are highest.?
Studies exploring the effects of the HPA axis on sleep initially focused on the direct effects of glucocorticoids on sleep rather than the effects of $\mathrm{CRH}$, but these results can now be reconciled given the known effects of CRH on sleep EEG and the indirect effects of glucocorticoids through $\mathrm{CRH}$ regulation. It is proposed that the effect of both exogenous and endogenous cortisol on SWS depends on cortisol levels capable of achieving maximal nocturnal CRH suppression. ${ }^{7}$ In addition, both the type of receptor activated by cortisol (MR or GR) and the location of the activated receptor influences CRH (see $§ 4$ ) and, consequently, EEG pattern. Since the MR antagonist canrenoate reduces SWS, whereas the mixed MR and GR agonist cortisol enhances SWS and inhibits REMS, it was postulated that the MR regulates SWS, whereas the GR regulates REMS. However, in another study it was shown that MR agonists and antagonists did not alter sleep EEG. ${ }^{62}$ Interestingly, in elderly controls, SWS increased after cortisol, although the number of MRs is known to decrease dramatically during ageing, ${ }^{63}$ suggesting that the effects of MRs on sleep are indirect.

It has been shown that continuous nocturnal infusion of cortisol ${ }^{64}$ and pulsatile i.v. ${ }^{65}$ administration increase SWS and reduce REMS in young normal subjects and in healthy elderly subjects.$^{63}$ Recently, several studies suggested that the effect of cortisol on sleep EEG depends on GR mediated feedback on $\mathrm{CRH}$, with elevated cortisol leading to suppression of CRH, resulting in an increase in SWS ${ }^{66}$ The effect of exogenous cortisol in decreasing SWS at high doses has not yet been explained. Since CRH and cortisol exert opposite effects on SWS and on $\mathrm{GH}$, it is more likely that these changes are mediated by negative feedback inhibition of endogenous $\mathrm{CRH}$ rather than by stimulation by cortisol. ${ }^{10}$ In patients with major depression, hourly injected cortisol $(1 \mathrm{mg} / \mathrm{kg}$ BW) increased duration and intensity of NREMS, particularly in male patients, and stimulated GH release, while REMS parameters were not affected by the infusion. ${ }^{67}$ Nevertheless, another study reported that glucocorticoids acutely decreased REM sleep and increased time spent awake. ${ }^{68}$

In Addison's disease, where production of corticosteroids is severely reduced, no major EEG disturbances of sleep have been reported..$^{69}$ In contrast, 
hypercortisolism and disturbed sleep are frequent symptoms in Cushing's disease and in depression. In Cushing's disease, SWS is decreased ${ }^{70,71}$ with increased sleep latency, enhanced waketime, and REMS disturbances. In depressed patients in whom both cortisol and ACTH were elevated throughout the night an increased number of awakenings, early morning awakenings, decrease of NREMS, and REMS disinhibition ${ }^{72}$ were observed.

Dexamethasone which activates GR has been shown to increase awakening. ${ }^{64}$ Administration of dexamethasone is thought to be equivalent to the administration of a high dose of cortisol. The mechanism for the effect of GC on sleep EEG is attributed to direct GR activation.

Consistent with the dose-related effect of glucocorticoids on MR versus GR activation, the administration of hydrocortisone to healthy males can at times increase SWS and at other times increase wakefulness and stage 1 sleep, the latter occurring at higher doses. ${ }^{64}$ Regarding GR activation in humans, in a study where methylprednisolone was administered to multiple sclerosis patients for ten days, a major portion of SWS was shifted from the first to the second sleep cycle, REMS latency was shortened, and REM frequency increased. ${ }^{73}$ Lately, the GR antagonist, mifepristone, was found to improve sleep and reduce HPA axis activity during acute administration and post-discontinuation in non depressed patients with chronic insomnia. ${ }^{74}$

\section{GALANIN}

Galanin is a peptide with widespread distribution in the mammalian brain and coexists in neurones with various neurotransmitters participating in sleep regulation. ${ }^{10}$ It is also known to stimulate GH via GHRH in man. Existing data support galanin's role in sleep regulation. Murck et a ${ }^{75}$ found that during pulsatile i.v. administration of galanin to young normal men, SWS and the duration of REMS periods increased, whereas the secretion of $\mathrm{GH}$ and cortisol remained unchanged.$^{76}$ As this effect could imply an antidepressive action, i.v. administration of galanin in patients with depression was studied, revealing significant changes in sleep-EEG parameters, mainly due to an increase in REM latency. This might imply an acute antidepressive effect of galanin, probably via a mechanism related to therapeutic sleep deprivation.

Recent studies on the possible role of galanin in the pathogenesis of panic disorder in females have focused on six single nucleotide polymorphisms (SNPs) within the gene coding for galanin, which are associated with either increased vulnerability or resistance. Since panic attacks can occur at any time, even during sleep, galanin and its receptors appear to be a promising target for the pharmacological therapy of these affective disorders. ${ }^{77}$

\section{ADENOSINE (ADE)}

ADE is an endogenous sleep-promoting substance which exerts its somnogenic action via activation of brain $\mathrm{A}(2 \mathrm{~A})$ receptors in the ventrolateral preoptic nucleus. ${ }^{78}$ The hypnogenic properties of ADE were first recognised in cats and rodents. In supporting the aforementioned, the most widely used psychoactive stimulant, caffeine, well known for its wake-promoting activity, is an ADE receptor antagonist.

A functional polymorphism of the ADE deaminase gene has been associated with interindividual variability in sleep architecture and the sleep EEG in humans. ${ }^{79}$ SWS is longer and sleep is deeper in the heterozygous carriers than in the homozygous. Heterozygous carriers of the polymorphism exhibit 20\%-30\% lower enzymatic activity in erythrocytes and leucocytes than homozygous individuals and may be at increased risk for developing autism. In contrast, the presence of a distinct polymorphism in the adenosine $\mathrm{A} 2 \mathrm{~A}$ receptor gene was shown to affect the EEG during sleep and wakefulness in a non-state-specific manner after caffeine intake by healthy volunteers.

\section{ARGININE VASOPRESSIN (AVP)}

The neuropeptide AVP is a major cofactor of $\mathrm{CRH}$ in the activation of the stress reaction. Chronic intranasal AVP improved sleep in normal elderly subjects as total sleep time, SWS, and REMS increased. ${ }^{80}$ Genetic variations in the AVP receptor $1 \mathrm{~b}$ gene (AVPR1b), via which AVP exerts its regulating effects on RMES, have been associated with a protective effect for recurrent major depression. ${ }^{81}$ 
Nocturia is a prevalent symptom that can adversely affect the quality of sleep. Low nocturnal AVP and urine osmolality may play a role in the pathophysiology of enuresis and nocturnal polyuria (NP).$^{82}$ The AVP analogue desmopressin has consistently shown nocturia and sleep quality improvement in patients with proven NP. ${ }^{83,84}$

\section{NEUROPEPTIDE Y (NPY)}

Besides GHRH, NPY is thought to act as a physiological antagonist of CRH. ${ }^{10}$ A variety of sleep-EEG effects of NPY have been reported. In humans, when NPY was repetitively administered i.v. in 20 young normal male subjects, it led to decreases in sleep latency and in the first REMS period as well as in increases in stage 2 sleep and sleep period. ${ }^{85}$ Cortisol and ACTH secretion were blunted. In patients with depression of both sexes and in age-matched controls sleep latency was shortened after NPY while cortisol and ACTH levels and the first REMS period remained unchanged. ${ }^{86}$

\section{VASOACTIVE INTESTINAL POLYPEPTIDE (VIP)}

As a member of the secretin-glucagon peptide family, VIP displays structural homology to GHRH, binding to the same receptors. ${ }^{13}$ This close relationship is particularly interesting since, in the mid $80 \mathrm{~s}$, VIP emerged as a peptide for which consistent sleep promoting activity (enhancement of both NREMS and REMS) was observed initially in rats. ${ }^{87}$ After pulsatile i.v. administration of 4 X50 $\mu \mathrm{g}$ VIP, NREMS-REMS cycles were decelerated in young normal males. Each cycle was prolonged, the cortisol nadir appeared earlier, and the GH acrophase was blunted. ${ }^{88}$ These data suggest that VIP affects the circadian clock, resulting in prolonged sleep cycles and an earlier occurrence of the cortisol nadir.

\section{PROLACTIN (PRL)}

Prolactin modulates REMS possibly through a central action. Thus, intracerebral injection of PRL or anti-PRL antibodies stimulates or inhibits REMS, respectively. ${ }^{89}$ It is likely that intracerebral PRL modulates REMS under physiological conditions, whereas pituitary PRL provides additional stimulating influence when PRL secretion is high, e.g., in stress. ${ }^{4,16}$ Human studies examining the effects of PRL on sleep are scarce; however, in patients with prolactinoma, SWS is increased selectively when compared to normal controls. ${ }^{90}$

\section{ESTROGENS - PROGESTERONE}

An abrupt decline in the sigma frequency range has been reported in women after the onset of menopause, whereas in men these changes develop more gradually. ${ }^{10}$ In postmenopausal women sleep-endocrine alterations associated with depression are accentuated. In a study of pre- and postmenopausal women with depression and matched controls, ${ }^{91}$ a decrease in SWS and an increase in REMS frequency was observed in post- but not in premenopausal women. An inverse correlation was found between the decrease in SWS as well as sleep continuity, and follicle stimulating hormone (FSH) secretion in patients with depression. These observations suggest a role of menopause in these sleep-EEG changes.

Much of the research on hormone replacement therapy (HRT) focuses on the role of estrogens and its positive effects on sleep in women after menopause. Compared to placebo, estrogen replacement therapy (ERT) has been shown to reduce insomnia. ${ }^{92}$ Other reported benefits of ERT include improvement in falling asleep, diminished nocturnal restlessness, and fewer awakenings. ${ }^{93}$ One possible explanation for these actions is that ERT relieves climacteric symptoms (e.g. hot flashes), leading to remarkable improvements in sleep. ${ }^{94}$ Another hypothesis is that ERT directly affects the circadian rhythm, or acts on sleep architecture, thus "normalising" the distribution of SWS in menopausal women, leading to a pattern resembling that of younger subjects. ${ }^{95}$ An additional effect of estrogens on sleep architecture is their effect on REMS, the increase in REMS being a consistent finding. ${ }^{94}$ In postmenopausal women ERT given for four weeks by skin patch enhanced REMS and reduced intermittent wakefulness during the first two sleep cycles compared to baseline values. A normal decrease in SWS and SWA from the first to the second cycle was observed.

Despite the above data showing effects of estrogens 
on sleep in postmenopausal women, the estrogen receptor-alpha (ER-alpha) genotypes (PvuII and XbaI polymorphisms) have been associated with vaginal dryness and hot flashes but not with sleep alterations. ${ }^{96}$ On the other hand, both case-control and prospective cohort studies have consistently linked night shift work with breast cancer risk and, more recently, endometrial cancer, both of which are highly sensitive to estrogens. ${ }^{97}$

Despite the proven effects of estrogens on sleep regulation, women starting HRT often also take progesterone to protect themselves against the harmful endometrial effects of estrogens. Studies of progesterone's effects on sleep have yielded variable results. ${ }^{94}$ There is some evidence that when progesterone is added to the HRT regimen, there is no improvement in sleep. ${ }^{98}$ However, there is a possibility that various types of progesterone can affect sleep differently. Montplaisir et a ${ }^{99}$ tested the sedating effects of progesterone by comparing HRT with two different progestogens: medroxyprogesterone acetate and micronized progesterone. They found that women treated with micronized progesterone had improvement in sleep efficiency. On the other hand, a Finnish study investigating the effects of estrogen-progestin treatment (EPT) on sleep in pre- and postmenopausal women, found that both groups receiving EPT had a significantly greater number of awakenings than the corresponding placebo group. Although, researchers could not conclude if EPT actually deteriorates sleep, available evidence indicates that no benefit from EPT in terms of sleep quality ${ }^{100}$ is achieved.

\section{DEHYDROEPIANDROSTERONE (DHEA)}

After a single oral dose of DHEA, REMS increased selectively in young normal men. ${ }^{101}$ After intraperitoneal (i.p.) infusion of DHEA sulphate (DHEAS) a dose-dependent effect on EEG potency was found. Interestingly, a DHEAS dosage of $50 \mathrm{mg} / \mathrm{kg}$ augmented EEG potency in the spindle-frequency range, whereas a dosage of $100 \mathrm{mg} / \mathrm{kg}$ had the opposite effect. Sleep architecture remained unchanged after either dosage of DHEAS. ${ }^{102}$ However, Dayal et $\mathrm{al}^{103}$ concluded that, compared with no hormone therapy, none of the supplemental hormone regimens (receiving DHEA daily over a period of 12 weeks) was associated with significant changes in sleep in 50 postmenopausal women.

\section{MELATONIN}

After almost 50 years of research the physiological role of melatonin still remains unclear. ${ }^{104}$ Nevertheless, the endogenous melatonin rhythm exhibits a close association with the endogenous circadian component of the sleep propensity rhythm. This may imply that melatonin is an internal sleep 'facilitator' in humans and therefore possibly useful in the treatment of insomnia and readjustment of circadian rhythms. There is evidence that administration of melatonin: (i) induces sleep when the homeostatic drive to sleep is insufficient and (ii) inhibits the drive for wakefulness emanating from the circadian pacemaker. Therefore, exogenous melatonin can act as a soporific agent, a chronohypnotic, and/or a chronobiotic. ${ }^{105}$

However, whether melatonin is causally involved in sleep mechanisms is shrouded in ambiguity. The ability to sleep is retained in the absence of detectable endogenous melatonin during the day and in tetraplegic patients. ${ }^{106}$ Melatonin production varies enormously between individuals and does not correlate with sleep quality or sleep-maintenance in elderly subjects without ${ }^{107}$ or with insomnia. ${ }^{108}$ By contrast, numerous laboratory studies have clearly demonstrated that administration of melatonin acutely affects sleep in humans. Exogenous melatonin elicits all the physiological effects which occur in the evening during endogenous melatonin secretion. Indeed, exogenous melatonin is most effective when endogenous levels are low during the biological day. It elicits time-dependent soporific effects, which have been corroborated with electrophysiological measures of sleepiness such as EEG theta activity during wakefulness. ${ }^{105}$ The most consistent effect found in those studies was that sleep latency was shorter after melatonin, even at rather low doses. ${ }^{109}$ On the other hand, sleep consolidation or sleep efficiency was not affected by night-time melatonin administration, whereas during daytime an improvement in sleep efficiency could be found.

Zhdanova ${ }^{110}$ mentions that, in general, melatonin can promote sleep in healthy humans if administered during habitual hours of wakefulness; it can be helpful in patients with insomnia and it can facilitate the 
effects of common hypnotics, thus reducing their effective dose and facilitating their withdrawal. Melatonin can acutely increase the homeostatic drive for sleep and ease the transition between wakefulness and sleep as well. On the other hand, Van den Heuvel et $\mathrm{a}^{111}$ claim that melatonin acts as a hypnotic only in those individuals for whom endogenous melatonin increases sleep propensity and its action is an appropriate consequence of environmental darkness. Under this perspective, melatonin can exert hypnoticlike effects but only under limited circumstances, depending on dose, time of administration, age, and other factors. ${ }^{112}$

Altered melatonin secretion has been found in Alzheimer's disease and in Parkinson's disease. Attempts to compensate for melatonin deficiency have shown that administration of this compound can improve sleep efficiency in both diseases. ${ }^{113}$ Despite these findings there are still discrepancies regarding its use in patients with Parkinson's disease. ${ }^{114}$ Melatonin also decreases sleep latency and number of awakenings per night and increases total sleep time in individuals with intellectual disabilities. ${ }^{15}$ Various lines of evidence show that depressed patients exhibit disturbances in both the amplitude and shape of the melatonin secretion rhythm and that exogenous melatonin can improve their quality of sleep. Moreover, a growing number of epidemiologic studies have evaluated the relationship between night shift work, as well as the effect of varying duration of sleep on peak melatonin secretion at night. Specifically, lower nightly melatonin levels have been shown in night workers. Although the evidence for an association between sleep duration and breast cancer risk is unclear, overall there is increasing support for a potentially important link between melatonin and breast cancer risk.${ }^{97}$ A possible link between diminished secretion of melatonin and increased exposure to light during night-time has been suggested. ${ }^{116}$ Ultimately, genome-wide association studies ${ }^{117-119}$ have shown that variation in the melatonin receptor 1B (MTNR1B) - a receptor known to be linked to the circadian rhythm of sleep-is associated with insulin and glucose concentrations as well as with the risk of type 2 diabetes (T2D). Blocking the melatonin ligand-receptor system has been suggested as a therapeutic avenue in T2D. ${ }^{117}$

A new treatment option in primary insomnia has been introduced with PR (prolonged-release) melatonin, which significantly improves morning alertness and quality of sleep compared with placebo in patients over the age of $55 .{ }^{120}$ Several clinical data are available for the melatonin agonists ramelteon, agomelatine, beta-methyl-6-chloromelatonin (TIK-301), and tasimelteon (VEC-162) in humans with regard to their contribution in the treatment of sleep-wake disorders. ${ }^{121}$ Ramelteon, the first to be approved for the treatment of chronic insomnia, has been shown to enhance subjective sleep quality in some, but not all, studies, ${ }^{122}$ especially in adults with generalized anxiety disorder, ${ }^{123}$ and in menopausal women. ${ }^{124}$ Agomelatine, which combines the properties of a 5HT(2C) antagonist and a melatonergic MT(1)/MT(2) receptor agonist, has been found to be very effective in re-setting the disturbed sleep/wake cycle and in improving the clinical status of major depressive disorder (MDD). ${ }^{125}$

\section{THYROTROPIN-RELEASING HORMONE (TRH)}

Clinical data suggest that sleep can be modulated by $\mathrm{TRH},{ }^{126}$ but the role of TRH in the regulation of sleep in humans has not yet been clarified. Hemmeter et $\mathrm{al}^{127}$ examined the effects of pulsatile administration of TRH on the sleep EEG pattern and the nocturnal secretions of cortisol and GH in healthy male subjects. In contrast to the well-known effects of $\mathrm{CRH}$ on the sleep pattern, TRH seems to exert only a weak effect on the sleep EEG, which is reflected in a slight decrease in sleep efficiency associated with a trend to wakefulness during the night. The activating, albeit weak, effect of TRH on the sleep EEG and nocturnal cortisol secretion in healthy volunteers confirms and adds to the results previously observed in animals. On the basis of these findings, it is likely that TRH may contribute to the disturbed sleep continuity seen in depressed patients, probably acting in a synergistic manner with CRH. In patients with hyperthyroidism, SWS is reduced ${ }^{72}$ whereas in MDD, TRH administration may lead to slight sleep EEG alteration ${ }^{128}$ or no alteration at all. ${ }^{129}$

\section{HYPOCRETIN/OREXIN}

The hypothalamic neuropeptides hypocretin-1 and 2 (also known as orexin A and B) have attracted 
tremendous interest since their discovery. In 2000, Nishino et $\mathrm{al}^{130}$ published the first report on hypocretin deficiency in human narcoleptics. Since then, several studies on the association between hypocretin and sleep-regulation have been published. ${ }^{131-135}$ Hypocretin signaling is crucial for maintaining wakefulness and regulating REMS. However, it is not required to generate (REM) sleep or wakefulness, as narcoleptic patients still show these vigilance states. The hypocretin/orexin system stabilises rather than generates vigilance states. As narcolepsy is characterised by sudden, inappropriate vigilance state transitions, hypocretin is needed to suppress such switches: it is necessary to keep the inherently unstable "sleep-wake switch" in the wake position. ${ }^{136}$

In humans, narcolepsy is associated with a specific variant of the human leukocyte antigen (HLA) complex. ${ }^{137}$ Genome-wide analysis shows that narcoleptic humans also exhibit a specific genetic mutation in the T-cell receptor alpha locus. ${ }^{138}$ These genetic anomalies may underlie the attack of the autoimmune system and the killing of the critical hypocretin neurons. Hence, the absence of hypocretin-producing neurons in narcoleptic humans may be the result of an autoimmune disorder. ${ }^{139}$ Cerebrospinal fluid (CSF) histamine levels are also reduced in human narcolepsy. As histamine is a wake-promoting amine known to decrease during sleep, decreased histamine could either reflect or mediate daytime sleepiness in these pathologies. ${ }^{140}$ Hypocretin deficiency is also found in symptomatic cases of narcolepsy and excessive daytime sleepiness with various neurological conditions such as Guillain-Barre syndrome, MA2-positive paraneoplastic syndrome, and neuromyelitis optica related disorder. ${ }^{141}$ These findings in humans have led to the establishment of a new diagnostic test of narcolepsy based on CSF hypocretin-1 levels.

Dysfunction of the hypocretin system has been reported in multiple sclerosis with hypothalamic lesions and hypersomnia. ${ }^{142}$ In patients with obstructive sleep apnea (OSA), lower levels of plasma orexin A have been found, especially in those who are ex- or current smokers. These results indicate that smoking may affect orexin levels in OSA patients with potential effect on their altered sleep patterns. ${ }^{143}$ In Parkinson's disease, orexin is most likely involved in clinically significant sleep attacks (SAs) ${ }^{144}$ and restless legs syndrome. ${ }^{145}$ Abrogation of D3 receptor stimulation may increase orexin and thereby inhibit SAs. ${ }^{144}$ A -909T/C gene polymorphism may explain in part the sudden onset of sleep in Parkinson's disease. ${ }^{146}$ A role for the orexin/hypocretin system in alertness and abnormal feeding behaviours in patients with attention-deficit/hyperactivity disorder (ADHD) has also been suggested; however, this hypothesis of over-activation of orexin neurons remains to be confirmed. ${ }^{147}$ Furthermore, in anorexia nervosa, abnormal activity of orexin (along with leptin) or their receptors may constitute one of the mechanisms of hyperactivity in these patients. ${ }^{148}$ Regarding obesity, multiple epidemiologic studies have shown an association between short sleep and higher body mass. ${ }^{149}$ Sleep disturbances are linked to a dysregulation of the neuroendocrine control of appetite. ${ }^{148}$

\section{SYNOPSIS}

The reported data have shown that various hormones (peptides and steroids) exert specific effects on the sleep EEG. Some peptides promote sleep while others increase wakefulness (Figure 1). Hormones that induce sleep (at least in males) include: GHRH, galanin, vasopressin, prolactin, estrogens and melatonin.

GHRH may have a direct role in promoting NREMS (especially duration and intensity of SWS) and REMS in humans with, however, diverse effects depending on gender and age. Interestingly, a synergism of GHRH and CRH is suggested in women, which may contribute to the increased prevalence of depression among females. Similarly, ghrelin lowers the time spent in stage 1 sleep, especially in young normal males.

Regarding cortisol, its effect on SWS depends on optimal cortisol levels to achieve maximal nocturnal $\mathrm{CRH}$ suppression. It is believed that the mineralocorticoid receptors regulate SWS, whereas the glucocorticoid receptors regulate REMS, although inconsistencies still exist. Several sleep alterations have been observed in diseases where cortisol production is altered (such as Addison's and Cushing's).

Galanin's enhancement of SWS and REMS both in young normal men and in patients with depression has indicated a possible acute antidepressive effect in 
the latter. In patients of both sexes with depression sleep latency is shortened after NPY. Data on the effect of VIP on sleep pattern in humans are inconsistent; VIP affects the circadian clock, resulting in prolonged sleep cycles and an earlier occurrence of the cortisol nadir. Although prolactin modulates REMS, human studies examining the effects of PRL on sleep are scarce; however, in patients with prolactinoma increases in SWS have been observed.

A role for menopause has been suggested for several sleep disruptions. In postmenopausal women with depression decreases in SWS and an increase in REMS frequency is observed. Compared to placebo, estrogen replacement therapy has been shown to reduce insomnia, relieve climacteric symptoms, and possibly act directly on the circadian rhythm or sleep architecture (via REMS modulation).

Melatonin secretion has been found to be altered in Alzheimer's and Parkinson's diseases and in MDD. Melatonin induces sleep when the homeostatic drive to sleep is insufficient, while it inhibits the drive for wakefulness emanating from the circadian pacemaker. However, the question as to whether melatonin is involved in sleep mechanisms has not been answered. Despite ambiguity, there is increasing support for a potentially important link between night shift work, melatonin secretion, and risk for breast cancer. In addition, genome-wide association studies show that variation in the melatonin receptor $1 \mathrm{~B}$, apart from its links with the circadian rhythm of sleep, is associated with a higher risk for type 2 diabetes.

Several hormones lead to sleep disruptions or produce only weak effects on sleep architecture, some of the effect showing gender and/or age dependence. SRIH impairs sleep in healthy elderly subjects, whereas it has no effect on young normal men, probably due to a decline of endogenous GHRH in the elderly. In contrast, the SRIH analogue, octreotide, immediately elicits suppression of NREMS and may be the culprit for sleep disruptions (increased daytime sleepiness, delayed sleep onset) in acromegalic patients. Similarly, CRH decreases SWS and increases wakefulness in young normal male subjects, with an increase in light sleep and awakenings, while it promotes REMS. However, findings are still inconsistent. DHEA increases REMS selectively in young normal men. Conversely,
ACTH suppresses REMS in normal controls, while an anticipatory increase in $\mathrm{ACTH}$ in the morning may facilitate spontaneous waking. The role of TRH in the regulation of sleep has not yet been clarified. Studies of progesterone's effects on sleep have yielded variable results. In contrast to progesterone, which when in the hormone replacement therapy regimen does not alter sleep, micronized progesterone itself leads to enhancement in sleep efficiency.

Hypocretin/orexin signalling is crucial for maintaining wakefulness and regulating REMS, as deduced from studies in narcoleptics.

All in all, the aforementioned evidence suggests that several hormones and hormonal agents may be involved in the regulation of sleep mechanisms in a manner proportional to the changes in their metabolic rhythm imposed by sleep. Given their interactions with the body's circadian clock, these molecules could be used in the future to treat sleep disorders. The present review has demonstrated that current evidence points to highly promising utilization of these molecules for treating sleep disorders, though more research is required before they are full introduced into clinical practice.

\section{REFERENCES}

1. Greenspan RJ, Tononi G, Cirelli C, Shaw PJ, 2001 Sleep and the fruit fly. Trends Neurosci 24: 142-145.

2. "The Regulation of Sleep", 2000 Borbély AA, Hayaishi O, Sejnowski TJ, Altman JS (eds). HFSP, Strasbourg, France.

3. Porkka-Heiskanen T, Alanko L, Kalinchuk A, Stenberg D, 2002 Adenosine and Sleep. Sleep Med Rev 6: 321332 .

4. Krueger JM, Majde JA, Obál F Jr, 2003 Sleep in host defense. Brain Behav Immun 17: S41-S47.

5. Akerstedt T, Nilsson PM, 2003 Sleep as restitution: an introduction. J Intern Med 254: 6-12.

6. Sateia MJ, Santulli RB, 1998 Sleep in palliative care. In: Doyle O, Hanks GWC, MacDonald N (eds). Oxford Textbook of Palliative Medicine (2nd Ed). New York: Oxford University Press; Chapter 8, pp, 731-746.

7. Buckley TM, Schatzberg AF, 2005 On the interactions of the HPA axis and sleep: Normal HPA axis and rhythm, exemplary sleep disorders. J Clin Endocrinol Metab 90: 3106-3114.

8. Borbély AA, 1982 A two process model of sleep regulation [Abstract]. Hum Neurobiol 1: 195-204.

9. Borbély AA, Achermann P, 1999 Sleep homeostasis and models of sleep regulation. J Biol Rhythms 14: 557- 
568.

10. Steiger A, 2003 Sleep and endocrinology. J Intern Med 254: 13-22.

11. Steiger A, 2007 Neurochemical regulation of sleep. J Psychiatr Res 41: 537-552.

12. Antonijevic IA, Murck H, Frieboes RM, et al, 1999 On the gender differences in sleep-endocrine regulation in young normal humans. Neuroendocrinol 70: 280-287.

13. Obál F Jr, Krueger JM, 2004 GHRH and sleep. Sleep Med Rev 8: 367-377.

14. Steiger A, Guldner J, Hemmeter U, et al, 1992 Effects of growth hormone-releasing hormone and somatostatin on sleep EEG and nocturnal hormone secretion in male controls. Neuroendocrinol 56: 566-573.

15. Marshall L, Mölle M, Böschen G, et al, 1996 Greater efficacy of episodic than continuous growth hormonereleasing hormone $(\mathrm{GHRH})$ administration in promting slow-wave sleep (SWS). J Clin Endocrinol Metab 81: 1009-1013.

16. Obál F Jr, Krueger JM, 2003 Biochemical regulation of non-rapideye-movement sleep. Front Biosci 8: d520550.

17. Kupfer DJ, Jarrett DB, Ehlers CL, 1991 The effect of GRF on the EEG sleep of normal males. Sleep 14: 8788.

18. Mathias S, Held K, Ising M, et al, 2007 Systemic growth hormone-releasing hormone (GHRH) impairs sleep in healthy young women. Psychoneuroendocrinol 32: 10211027.

19. Kerkhofs M, Van Cauter E, Van Onderbergen A, et al, 1993 Sleep-promoting effects of growth hormonereleasing hormone in normal men. Am J Physiol 264: E594-E598.

20. Schier T, Guldner J, Colla M, Holsboer F, Steiger A, 1997 Changes in sleep-endocrine activity after growth hormone-releasing hormone depend on time of administration. J Neuroendocrinol 9: 201-205.

21. Steiger A, 2003 Sleep and endocrine regulation. Front Biosci 8: s358-s376.

22. Perras B, Marshall L, Köhler G, Born J, Fehm HL, 1999 Sleep and endocrine changes after intranasal administration of growth hormone-releasing hormone in young and aged humans. PNEC 24: 743-757.

23. Schüssler P, Yassouridis A, Uhr M, et al, 2006 Growth hormone-releasing hormone and corticotropin-releasing hormone enhance non-rapid-eye-movement sleep after sleep deprivation. Am J Physiol Endocrinol Metab 291: E549-556.

24. Guldner J, Schier T, Friess E, et al, 1997 Reduced efficacy of growth hormone-releasing hormone in modulating sleep endocrine activity in the elderly. Neurobiol Aging 18: 491-495.

25. Antonijevic IA, Murck H, Frieboes RM, Barthelmes J, Steiger A, 2000 Sexually dimorphic effects of GHRH on sleep endocrine activity in patients with depression and normal controls - part I: the sleep EEG. Sleep Research
Online 3: 5-13.

26. Obál Jr F, Payne L, Kapas L, et al, 1991 Inhibition of growth hormone-releasing factor suppresses both sleep and growth hormone secretion in the rat. Brain Res 557: 149-153.

27. Zhang J, Obál F Jr, Zheng T, et al, 1999 Intrapreoptic microinjection of GHRH or its antagonist alters sleep in rats. J Neurosci 19: 2187-2194.

28. Obál F Jr, Payne L, Opp M, et al, 1992 Growth hormone-releasing hormone antibodies suppress sleep and prevent enhancement of sleep after sleep deprivation. Am J Physiol 263: R1078-R1085.

29. Merriam GR, Schwartz RS, Vitiello MV, 2003 Growth hormone-releasing hormone and growth hormone secretagogues in normal aging. Endocrine 22: 41-48.

30. Doga M, Bonadonna S, Burattin A, Giustina A, 2001 Ectopic secretion of growth hormone-releasing hormone (GHRH) in neuroendocrine tumors: relevant clinical aspects. Ann Oncol 12: Suppl 2: S89-S94.

31. Kojima M, Hosoda H, Date Y, et al, 1999 Ghrelin is a growth hormone-releasing acylated peptide from stomach. Nature 402: 656-660.

32. Ghigo E, Broglio F, Arvat E, et al, 2005 Ghrelin: more than a natural GH secretagogue and/or an orexigenic factor. Clin Endocrinol 62: 1-17.

33. Korbonits M, Goldstone AP, Gueorguiev M, Grossman AB, 2004 Ghrelin - a hormone with multiple functions. Front Neuroendocrinol 25: 27-68.

34. van der Lely AJ, Tschop M, Heiman ML, Ghigo E, 2004 Biological, physiological, pathophysiological, and pharmacological aspects of ghrelin. Endocrin Rev 25: 426-457.

35. Arvat E, Maccario M, Di Vito L, et al, 2001 Endocrine activities of ghrelin, a natural growth hormone secretagogue (GHS), in humans: comparison and interactions with hexarelin, a nonnatural peptidyl GHS, and GH-releasing hormone. J Clin Endocrinol Metab 86: 1169-1174.

36. Weikel JC, Wichniak A, Ising M, et al, 2003 Ghrelin promotes slow-wave sleep in humans. Am J Physiol Endocrinol Metab 284: E407-E415.

37. Schuessler P, Uhr M, Ising M, et al, 2005 Nocturnal ghrelin levels - relationship to sleep EEG, the levels of growth hormone, ACTH and cortisol - and gender differences. J Sleep Res 14: 329-336.

38. Kluge M, Schüssler P, Zuber V, Yassouridis A, Steiger A, 2007 Ghrelin administered in the early morning increases secretion of cortisol and growth hormone without affecting sleep. Psychoneuroendocrinol 32: 287-292.

39. Copinschi G, Leproult R, Van Onderbergen A, et al, 1997 Prolonged oral treatment with MK-677, a novel growth hormone secretagogue, improves sleep quality in man. Neuroendocrinol 66: 278-286.

40. Frieboes RM, Murck H, Antonijevic IA, Steiger A, 1999 Effects of growth hormone-releasing peptide- 6 on the nocturnal secretion of GH, ACTH and cortisol and on 
the sleep EEG in man: role of routes of administration. J Neuroendocrinol 11: 473-478.

41. Moreno-Reyes R, Kerkhofs M, L'Hermite-Baleriaux M, et al, 1998 Evidence against a role for the growth hormone-releasing peptide axis in human slow-wave sleep regulation. Am J Physiol 274: E779-E784.

42. Frieboes RM, Antonijevic IA, Held K, et al, 2004 Hexarelin decreases slow-wave sleep and stimulates the secretion of $\mathrm{GH}, \mathrm{ACTH}$, cortisol and prolactin during sleep in healthy volunteers. Psychoneuroendocrinol 29: 851-860.

43. Simi L, Pinzani P, Raggi CC, et al, 2007 Influence of 17q gain and promoter polymorphisms on mRNA expression of somatostatin receptor type 2 in neuroblastoma. Clin Chim Acta 384: 149-154.

44. Frieboes RM, Murck H, Schier T, Holsboer F, Steiger A, 1997 Somatostatin impairs sleep in elderly human subjects [Abstract]. Neuropsychopharmacol 16: 339345.

45. Steiger A, Weikel J, Held K, Schmid D, Ziegenbein M, 2002 Arginine improves sleep in elderly men [Abstract]. Sleep 25: A203.

46. Ziegenbein M, Murck H, Künzel H, Held K, Steiger A, 1999 Sleep-endocrine effects of growth hormone-releasing hormone (GHRH) in patients with obsessive-compulsive disorder (OCD). Pharmacopsychiatry 32: 220.

47. de Lecea L, Bourgin P, 2008 Neuropeptide interactions and REM sleep: a role for Urotensin II? Peptides 29: 845-851.

48. de Lecea L, 2005 Cortistatin: a natural somatostatin analog. J Endocrinol Invest 28: 10-14.

49. van der Klaauw AA, Pereira AM, van Kralingen KW, Rabe KF, Romijn JA, 2008 Somatostatin analog treatment is associated with an increased sleep latency in patients with long-term biochemical remission of acromegaly. Growth Horm IGF Res 18: 446-453.

50. Holsboer F, von Bardeleben U, Steiger A, 1988 Effects of intravenous corticotropin-releasing hormone upon sleep-related growth hormone surge and sleep EEG in man. Neuroendocrinol 48: 32-38.

51. Steiger A, Holsboer F, 1997. Neuropeptides and human sleep. Sleep 20: 1038-1052.

52. Antonijevic IA, Murck H, Frieboes RM, et al, 1999 Hyporesponsiveness of the pituitary to $\mathrm{CRH}$ during slow wave sleep is not mimicked by systemic GHRH. Neuroendocrinol 69: 88-96.

53. Vgontzas AN, Bixler EO, Wittman AM, et al, 2001 Middle-aged men show higher sensitivity of sleep to the arousing effects of corticotropin-releasing hormone than young men: clinical implications. J Clin Endocrinol Metab 86: 1489-1495.

54. Chang FC, Opp MR, 2001 Corticotropin-releasing hormone $(\mathrm{CRH})$ as a regulator of waking. Neurosci Biobehav Rev 25: 445-453.

55. Held K, Kunzel H, Ising M, et al, 2004 Treatment with the CRH1-receptorantagonist R121919 improves sleep-
EEG in patients with depression. J Psychiatr Res 38: 129-136.

56. Antonijevic I, 2007. HPA axis and sleep: identifying subtypes of major depression. Stress 11: 15-27.

57. Liu Z, Zhu F, Wang G, et al, 2007 Association study of corticotropin-releasing hormone receptor1 gene polymorphisms and antidepressant response in major depressive disorders. Neurosci Lett 414: 155-158.

58. Fehm HL, Späth-Schwalbe E, Pietrowsky R, et al, 1993 Entrainment of nocturnal pituitary-adrenocortical activity to sleep processes in man - a hypothesis. Exp Clin Endocrinol 101: 267-276.

59. Born J, Hansen K, Marshall L, et al, 1999 Timing the end of nocturnal sleep. Nature 397: 29-30.

60. Steiger A, 2002. Sleep and the hypothalamo-pituitaryadrenocortical system. Sleep Med Rev 6: 125-138.

61. Alexis MN, Stylianopoulou F, Kitraki E, Sekeris CE, 1983 The distribution and properties of the glucocorticoid receptor from rat brain and pituitary. J Biol Chem 258: 4710-4714.

62. Friess E, Wiedemann K, Steiger A, et al, 1995 The hypothalamic-pituitary-adrenocortical system and sleep in man. Adv Neuroimmunol 5: 111-125.

63. Bohlhalter S, Murck H, Holsboer F, Steiger A, 1997 Cortisol enhances non-REM sleep and growth hormone secretion in elderly subjects. Neurobiol Aging 18: 423429.

64. Born J, DeKloet ER, Wenz H, Kern W, Fehm HL, 1991 Gluco- and antimineralocorticoid effects on human sleep: a role of central corticosteroid receptors. Am J Physiol 260: E183-188.

65. Friess E, von Bardeleben U, Wiedemann K, Lauer C, Holsboer F, 1994 Effects of pulsatile cortisol infusion on sleep-EEG and nocturnal growth hormone release in healthy men. J Sleep Res 3: 73-79.

66. Friess E, Tagaya H, Grethe C, Trachsel L, Holsboer F, 2004 Acute cortisol administration promotes sleep intensity in man. Neuropsychopharmacol 29: 598-604.

67. Schmid DA, Brunner H, Lauer CJ, et al, 2008 Acute cortisol administration increases sleep depth and growth hormone release in patients with major depression. $\mathrm{J}$ Psychiatr Res 42: 991-999.

68. Gillin JC, Jacobs LS, Fram DH, Snyder F, 1972 Acute effect of a glucocorticoid on normal human sleep [Abstract]. Nature 237: 398-399.

69. Gillin JC, Jacobs LS, Snyder F, et al, 1974 Effects of ACTH on the sleep of normal subjects and patients with Addison's disease. Neuroendocrinology 15: 21-31.

70. Krieger DT, Glick SM, 1974 Sleep EEG stages and plasma growth hormone concentration in states of endogenous and exogenous hypercortisolemia or ACTH elevation. J Clin Endocrinol Metab 39: 986-1000.

71. Shipley JE, Schteingart DE, Tandon R, et al, 1992 Sleep architecture and sleep apnea in patients with Cushing's disease. Sleep 15: 514-518.

72. Steiger A 2007 Neuroendocrinology of Sleep. In: Lajtha 
A, Blaustein JD (Eds). Handbook of Neurochemistry and Molecular Neurobiology, Plenum Press, New York, pp, 897-926.

73. Antonijevic IA, Steiger A, 2003 Depression-like changes of the sleep-EEG during high dose corticosteroid treatment in patients with multiple sclerosis. PNEC 28: 780795 .

74. Buckley T, Duggal V, Schatzberg AF, 2008 The acute and post-discontinuation effects of a glucocorticoid receptor (GR) antagonist probe on sleep and the HPA axis in chronic insomnia: a pilot study. J Clin Sleep Med 4: $235-241$.

75. Murck H, Held K, Ziegenbein M, et al, 2004 Intravenous administration of the neuropeptide galanin has fast antidepressant efficacy and affects the sleep EEG. PNEC 29: 1205-1211.

76. Murck H, Antonijevic IA, Frieboes RM, et al, 1999 Galanin has REM-sleep deprivation-like effects on the sleep EEG in healthy young men. J Psychiatr Res 33: 225-232.

77. Unschuld PG, Ising M, Erhardt A, et al, 2008 Polymorphisms in the galanin gene are associated with symptomseverity in female patients suffering from panic disorder. J Affect Disord 105: 177-184.

78. Gallopin T, Luppi PH, Cauli B, et al, 2005 The endogenous somnogen adenosine excites a subset of sleep-promoting neurons via $\mathrm{A} 2 \mathrm{~A}$ receptors in the ventrolateral preoptic nucleus. Neuroscience 134: 1377-1390.

79. Rétey JV, Adam M, Honegger E, et al, 2005 A functional genetic variation of adenosine deaminase affects the duration and intensity of deep sleep in humans. Proc Natl Acad Sci U S A 102: 15676-15681.

80. Perras B, Pannenborg H, Marshall L, et al, 1999 Beneficial treatment of age-related sleep disturbances with prolonged intranasal vasopressin. J Clin Psychopharmacol 19: $28-36$

81. van West D, Del-Favero J, Aulchenko Y, et al, 2004 A major SNP haplotype of the arginine vasopressin $1 \mathrm{~B}$ receptor protects against recurrent major depression. Mol Psychiatry 9: 287-292.

82. Abdelfatah D, Shaker H, Ismail M, et al, 2009 Nocturnal polyuria and nocturnal arginine vasopressin (AVP): A key factor in the pathophysiology of monosymptomatic nocturnal enuresis. Neurourol Urodyn 28: 506-509.

83. Gozmen S, Keskin S, Akil I, 2008 Enuresis nocturna and sleep quality. Pediatr Nephrol 23: 1293-1296.

84. Schneider T, de la Rosette JJ, Michel MC, 2009 Nocturia: a non-specific but important symptom of urological disease. Int J Urol 16: 249-256.

85. Antonijevic IA, Murck H, Bohlhalter S, et al, 2000 NPY promotes sleep and inhibits ACTH and cortisol release in young men. Neuropharmacol 39: 1474-1481.

86. Held K, Antonijevic I, Murck H, Kuenzel H, Steiger A, 2006 Neuropeptide Y (NPY) shortens sleep latency but does not suppress ACTH and cortisol in depressed patients and normal controls. Psychoneuroendocrinol
31: 100-107.

87. Drucker-Colin R, Bernal-Pedraza J, Fernandez-Cancino F, et al, 1984 Is vasoactive intestinal polypeptide (VIP) a sleep factor? [Abstract]. Peptid 5: 837-840.

88. Murck H, Guldner J, Colla-Müller M, et al, 1996 VIP decelerates non-REM-REM cycles and modulates hormone secretion during sleep in men. Am J Physiol 271: R905-R911.

89. Roky R, Obál F Jr, Valatx JL, et al, 1995 Prolactin and rapid eye movement sleep regulation. Sleep 18: 536542 .

90. Frieboes RM, Murck H, Stalla GK, Antonijevic IA, Steiger A, 1998 Enhanced slow wave sleep in patients with prolactinoma. J Clin Endocrinol Metab 83: 27062710.

91. Antonijevic IA, Murck H, Frieboes RM, Uhr M, Steiger A, 2003 On the role of menopause for sleep-endocrine alterations associated with major depression. PNEC 28: 401-418.

92. Wiklund I, Karlberg J, Mattsson L-A, 1993 Quality of life of post-menopausal women on a regimen of transdermal estradiol therapy: a double-blind placebo-controlled study [Abstract]. Am J Obstet Gynecol 168: 824-830.

93. Polo-Kantola P, Erkkola R, Helenius H, Irjala K, Polo O, 1998 When does estrogen replacement therapy improve sleep quality? Am J Obstet Gynecol 178: 1002-1009.

94. Shin K, Shapiro C, 2003 Menopause, sex hormones, and sleep. Bibolar Disord 5: 106-109.

95. Antonijevic IA, Stalla GK, Steiger A, 2000 Modulation of the sleep electroencephalogram by estrogen replacement in postmenopausal women. Am J Obstet Gynecol 182: 277-282.

96. Malacara JM, Pérez-Luque EL, Martínez-Garza S, et al, 2004 The relationship of estrogen receptor-alpha polymorphism with symptoms and other characteristics in post-menopausal women. Maturitas 49:163-169.

97. Viswanathan AN, Schernhammer ES, 2009 Circulating melatonin and the risk of breast and endometrial cancer in women. Cancer Lett 281: 1-7.

98. Natale V, Albertazzi P, Zini M, Di Marco R, 2001 Exploration of cyclical changes in memory and mood in postmenopausal women taking sequential combined oestrogen and progestogen preparations. Br J Obstet Gynaecol 108: 286-290.

99. Montplaisir J, Lorrain J, Denesle R, Petit D, 2001 Sleep in menopause. differential effects of two forms of hormone replacement therapy. Menopause 8: 10-16.

100. Kalleinen N, Polo O, Himanen SL, Joutsen A, PoloKantola P, 2008 The effect of estrogen plus progestin treatment on sleep: a randomized, placebo-controlled, double-blind trial in premenopausal and late postmenopausal women. Climacteric 11: 233-243.

101. Friess E, Trachsel L, Guldner J, et al, 1995 DHEA administration increases rapid eye movement sleep and EEG power in the sigma frequency range. Am J Physiol 268: E107-E113. 
102. Schiffelholz T, Holsboer F, Lancel M, 2000 High doses of systemic DHEA-sulfate do not affect sleep structure and elicit moderate changes in non-REM sleep. Physiol Behav 69: 399-404.

103. Dayal M, Sammel MD, Zhao J, et al, 2005 Supplementation with DHEA: effect on muscle size, strength, quality of life, and lipids [Abstract]. J Womens Health (Larchmt) 14: 391-400.

104. Nikolakopoulou D, Stamatakis A, 2009 The Role of Melatonin in the Pathology of the Cardiovascular System. Nosileftiki, 48: 143-149.

105. Cajochen C, Kräuchi K, Wirz-Justice A, 2003 Role of melatonin in the regulation of human circadian rhythms and sleep. J Neuroendocrinol 15: 432-437.

106.Zeitzer JM, Ayas NT, Shea SA, Brown R, Czeisler CA, 2000 Absence of detectable melatonin and preservation of cortisol and thyrotropin rhythms in tetraplegia. J Clin Endocrinol Metab 85: 2189-2196.

107. Youngstedt SD, Kripke DF, Elliott JA, 1998 Melatonin excretion is not related to sleep in the elderly. J Pineal Res 24: 142-145.

108. Hughes RJ, Sack RL, Lewy AJ, 1998 The role of melatonin and circadian phase in age-related sleep-maintenance insomnia: assessment in a clinical trial of melatonin replacement. Sleep 21: 52-68.

109. Zhdanova IV, Wurtman RJ, Morabito C, Piotrovska VR, Lynch HJ, 1996 Effects of low oral doses of melatonin, given 2-4 hours before habitual bedtime, on sleep in normal young humans. Sleep 19: 423-431.

110. Zhdanova IV, 2005. Melatonin as a hypnotic: Pro. Sleep Med Rev 9: 51-65.

111. Van den Heuvel CJ, Ferguson SA, Mila Macchi M, Dawson D, 2005 Melatonin as a hypnotic: Con. Sleep Med Rev 9: 71-80.

112. Gehrman PR, Connor DJ, Martin JL, et al, 2009 Melatonin fails to improve sleep or agitation in double-blind randomized placebo-controlled trial of institutionalized patients with Alzheimer disease. Am J Geriatr Psychiatry 17: 166-169.

113. Srinivasan V, Pandi-Perumal SR, Cardinali DP, et al, 2006 Melatonin in Alzheimer's disease and other neurodegenerative disorders. Behav Brain Funct 2: 15.

114. Gehrman PR, Connor DJ, Martin JL, et al, 2009 Melatonin fails to improve sleep or agitation in double-blind randomized placebo-controlled trial of institutionalized patients with Alzheimer disease. Am J Geriatr Psychiatry 17: 166-169.

115. Braam W, Smits MG, Didden R, et al, 2009 Exogenous melatonin for sleep problems in individuals with intellectual disability: a meta-analysis. Dev Med Child Neurol 51: 340-349.

116. Srinivasan V, Spence DW, Pandi-Perumal SR, et al, 2008 Therapeutic actions of melatonin in cancer: possible mechanisms. Integr Cancer Ther 7: 189-203.

117. Lyssenko V, Nagorny CL, Erdos MR, et al, 2009 Common variant in MTNR1B associated with increased risk of type 2 diabetes and impaired early insulin secretion. Nat Genet 41: 82-88.

118. Bouatia-Naji N, Bonnefond A, Cavalcanti-Proença C, et al, 2009 A variant near MTNR1B is associated with increased fasting plasma glucose levels and type 2 diabetes risk. Nat Genet 41: 89-94.

119. Prokopenko I, Langenberg C, Florez JC, et al, 2009 Variants in MTNR1B influence fasting glucose levels. Nat Genet 41: 77-81.

120. Wade A, Downie S, 2008 Prolonged-release melatonin for the treatment of insomnia in patients over 55 years. Expert Opin Investig Drugs 17: 1567-1572.

121. Rivara S, Mor M, Bedini A, Spadoni G, Tarzia G, 2008 Melatonin receptor agonists: SAR and applications to the treatment of sleep-wake disorders. Curr Top Med Chem 8: 954-968.

122.Simpson D, Curran MP, 2008 Ramelteon: a review of its use in insomnia. Drugs 68: 1901-1919.

123. Gross PK, Nourse R, Wasser TE, 2009 Ramelteon for insomnia symptoms in a community sample of adults with generalized anxiety disorder: an open label study. J Clin Sleep Med 5: 28-33.

124. Dobkin RD, Menza M, Bienfait KL, et al, 2009 Ramelteon for the treatment of insomnia in menopausal women. Menopause Int 15: 13-18.

125. Srinivasan V, Pandi-Perumal SR, Trakht I, et al, 2009 Pathophysiology of depression: role of sleep and the melatonergic system. Psychiatry Res 165: 201-214.

126. Nishino S, Arrigoni J, Shelton J, et al, 1997 Effects of thyrotropin-releasing hormone and its analogs on daytime sleepiness and cataplexy in canine narcolepsy. J Neurosci 17: 6401-6408.

127. Hemmeter U, Rothe B, Guldner J, Holsboer F, Steiger A, 1998 Effects of thyrotropin-releasing hormone on the sleep EEG and nocturnal hormone secretion in male volunteers. Neuropsychobiol 38: 25-31.

128. Staner L, Duval F, Haba J, et al, 2003 Disturbances in hypothalamo pituitary adrenal and thyroid axis identify different sleep EEG patterns in major depressed patients. J Psychiatr Res 37: 1-8.

129. Staner L, Duval F, Calvi-Gries F, et al, 2001 Morning and evening TSH response to TRH and sleep EEG disturbances in major depressive disorder. Prog Neuropsychopharmacol Biol Psychiatry 25: 535-547.

130. Nishino S, Ripley B, Overeem S, et al, 2000 Hypocretin (orexin) deficiency in human narcolepsy. Lancet 355: 39-40.

131. Taylor MM, Samson WK, 2003 The other side of the orexins: endocrine and metabolic actions. Am J Physiol Endocrinol Metab 284: E13-E17.

132. Nishino S, 2003 The Hypocretin/Orexin System in Health and Disease. Biol Psychiatry 54: 87-95.

133. Nishino S, Yoshida Y, 2003 History and perspectives of hypocretin/orexin research in sleep medicine. Sleep Biol Rhyth 1: 43-54.

134. Watson CJ, Soto-Calderon H, Lydic R, Baghdoyan HA, 
2008 Pontine reticular formation (PnO) administration of hypocretin-1 increases PnO GABA levels and wakefulness. Sleep 31: 453-464.

135. Nishino S, 2007. The hypocretin/orexin receptor: therapeutic prospective in sleep disorders. Expert Opin Investig Drugs 16: 1785-1797.

136. Saper CB, Chou TC, Scammell TE, 2001 The sleep switch: hypothalamic control of sleep and wakefulness. Trends Neurosci 24: 726-731.

137. Klein J, Sato A, 2000 The HLA system. Second of two parts. N Engl J Med 343: 782-786.

138. Hallmayer J, Faraco J, Lin L, et al, 2009 Narcolepsy is strongly associated with the $\mathrm{T}$-cell receptor alpha locus. Nat Genet 41: 708-711.

139. "Narcolepsy is an autoimmune disorder, Stanford researcher says". EurekAlert. American Association for the Advancement of Science. 2009-05-03. http://www. eurekalert.org/pub_releases/2009-05/sumc-nia042809. php. Retrieved on 2009-07-12.

140. Nishino S, Sakurai E, Nevsimalova S, et al, 2009 Decreased CSF histamine in narcolepsy with and without low CSF hypocretin-1 in comparison to healthy controls. Sleep 32: 175-180.

141. Nishino S, Okuro M, Kotorii N, et al, 2009 Hypocretin/ orexin and narcolepsy new basic and clinical insights. Acta Physiol (Oxf) Jun 25. [Epub ahead of print]

142. Knudsen S, Jennum PJ, Korsholm K, et al, 2008 Normal levels of cerebrospinal fluid hypocretin-1 and daytime sleepiness during attacks of relapsing-remitting multiple sclerosis and monosymptomatic optic neuritis. Mult Scler 14: 734-738.

143. Aksu K, Firat Güven S, Aksu F, et al, 2009 Obstructive sleep apnoea, cigarette smoking and plasma orexin-A in a sleep clinic cohort. J Int Med Res 37: 331-340.

144. Asai H, Hirano M, Furiya Y, et al, 2009 Cerebrospinal fluid-orexin levels and sleep attacks in four patients with Parkinson's disease. Clin Neurol Neurosurg 111: 341-344.

145. Poceta JS, Parsons L, Engelland S, et al, 2009 Circadian rhythm of CSF monoamines and hypocretin-1 in restless legs syndrome and Parkinson's disease. Sleep Med 10: 129-133.

146. Rissling I, Körner Y, Geller F, et al, 2005 Preprohypocretin polymorphisms in Parkinson disease patients reporting "sleep attacks". Sleep 28: 871-875.

147. Cortese S, Konofal E, Lecendreux M, 2008 Alertness and feeding behaviors in ADHD: does the hypocretin/orexin system play a role? Med Hypotheses 71: 770-775.

148. Baranowska B, Baranowska-Bik A, Bik W, et al, 2008 The role of leptin and orexins in the dysfunction of hypothalamo-pituitary-gonadal regulation and in the mechanism of hyperactivity in patients with anorexia nervosa. Neuro Endocrinol Lett 29: 37-40.

149. Knutson KL, Van Cauter E, 2008 Associations between sleep loss and increased risk of obesity and diabetes. Ann N Y Acad Sci 1129: 287-304. 